\title{
O USO DOS RESULTADOS DO SARESP COMO INSTRUMENTO DE GESTÃO ESCOLAR: BOLETIM PEDAGÓGICO E AVALIAÇÃO INSTITUCIONAL
}

\author{
EL USO DE LOS RESULTADOS DE SARESP COMO INSTRUMENTO DE GESTIÓN \\ ESCOLAR: BOLETÍN PEDAGÓGICO Y EVALUACIÓN INSTITUCIONAL
}
THE USE OF SARESP RESULTS AS A SCHOOL MANAGEMENT INSTRUMENT: PEDAGOGICAL BULLETIN AND INSTITUTIONAL EVALUATION

\author{
Claudia Pereira de Pádua SABIA ${ }^{1}$
}

RESUMO: O Sistema de Avaliação do Rendimento Escolar de São Paulo foi criado em 1996. O objetivo deste estudo é identificar se os resultados do SARESP 2016 foram discutidos entre gestores e professores e quais foram os encaminhamentos; verificar também se as escolas realizam a avaliação institucional de modo a subsidiar a gestão escolar. A metodologia utilizada é a pesquisa bibliográfica, pesquisa documental e a coleta de dados. Como resultados, o estudo apresenta que os alunos das escolas com proficiência básico ou abaixo do básico tiveram como encaminhamento, basicamente, a recuperação no contraturno no Programa Novo Mais Educação e aspectos que a comprometem. Em relação à Avaliação Institucional o que é denominado como tal não consiste "de fato" em um processo de busca pela compreensão da realidade escolar. É utilizado apenas um Instrumento de AI fornecido pela Diretoria de Ensino que consiste em um questionário aplicado no último dia de aula.

PALAVRAS-CHAVE: Avaliação dos sistemas de ensino. SARESP. Avaliação institucional. Planejamento didático-pedagógico.

RESUMEN: El Sistema de Evaluación del Desempeño Escolar de São Paulo se creó en 1996. El objetivo de este estudio es identificar si los resultados de SARESP 2016 fueron discutidos entre gerentes y maestros y cuáles fueron las referencias; Compruebe también si las escuelas llevan a cabo la evaluación institucional para subsidiar la gestión escolar. La metodología utilizada es la investigación bibliográfica, la investigación documental y la recopilación de datos. Como resultado, el estudio muestra que los estudiantes de escuelas con dominio básico o inferior al básico tuvieron como referencia básicamente la recuperación durante el día en el Programa Educativo Novo Mais y los aspectos que lo comprometen. Con respecto a la evaluación institucional, lo que se denomina como tal no consiste "de hecho" en un proceso de búsqueda de comprender la realidad escolar. Solo se utiliza un Instrumento de IA proporcionado por la Junta Directiva y consiste en un cuestionario aplicado el último día de clase.

PALABRAS CLAVE: Evaluación de sistemas educativos. SARESP. Evaluación institucional. Planificación didáctico-pedagógica.

${ }^{1}$ Universidade Estadual Paulista (UNESP), Marília - SP - Brasil. Professora Assistente do Departamento de Administração e Supervisão Escolar (DASE) da Faculdade de Filosofia e Ciências (FFC). ORCID: https://orcid.org/0000-0001-8173-6420. E-mail: claudia.sabia@unesp.br ou fsabia@uol.com.br

RPGE- Revista on line de Política e Gestão Educacional, Araraquara, v. 23, n. 3, p. 665-679, set./dez., $2019 \quad$ ISSN: 1519-9029 
ABSTRACT: The São Paulo School Performance Assessment System was created in 1996. The aim of this study is to identify if the results of SARESP (Portuguese initials) 2016 were discussed between managers and teachers and what were the referrals; also check if the schools carry out the institutional evaluation in order to subsidize the school management. The methodology used is bibliographic research, documentary research and data collection. As a result, the study shows that students from schools with basic or below basic proficiency had as a referral, basically, the recovery during the other shift in the Programa Novo Mais Educação and aspects that compromise it. Regarding Institutional Evaluation, what is termed as such does not consist "in fact" in a process of seeking to understand the school reality. Only one AI Instrument provided by the Board of Directors is used and consists of a questionnaire applied on the last day of class.

KEYWORDS: Evaluation of education systems. SARESP. Institutional evaluation. Didacticpedagogical planning.

\section{Introdução}

Cabe explicitar que o foco neste trabalho é o SARESP, ou seja, uma avaliação do sistema estadual paulista, que no ano de 2017 completou sua vigésima edição. Consideramos que a avaliação de larga escala percorreu no Brasil um longo caminho e a partir da década de 1990, vêm sendo implementadas de forma sistemática avaliações nacionais, estaduais e nos últimos anos também municipais.

De acordo com Bauer et al. (2015, p. 328) a expansão das iniciativas de avaliação em larga escala, implementadas pelo governo federal ou pelos governos estaduais foram intensificadas após a criação em 2007, do Índice de Desenvolvimento da Educação Básica IDEB, pelo Instituto Nacional de Estudos e Pesquisas Educacionais Anísio Teixeira - INEP.

Em estudo recente a autora citada informa que no âmbito estadual, dos 27 estados brasileiros, vinte já possuem sistemas próprios de avaliação e 1.573 municípios já possuem também seus sistemas de avaliação, sendo maior parte criados a partir de 2005. O estudo citado apresenta também evidências da consolidação da avaliação em larga escala como instrumento de gestão educacional dos municípios (BAUER et al., 2017, p. 5).

A utilização da avaliação de larga escala como instrumento gestão dos municípios e estados vem sendo adotada no Brasil algumas décadas atrás do que ocorreu em outros países do mundo. Particularmente nos Estados Unidos, o processo de responsabilização foi iniciado a partir do Relatório Coleman em 1966.

Segundo Ravitch (2002) “o interesse na prestação de contas pode ser atribuído ao relatório histórico Equality of Educational Opportunity de 1966, conhecido como o relatório 
Coleman pelo seu principal autor, o sociólogo James Coleman” (RAVITCH, 2002, p.14, tradução nossa).

A autora destaca que o estudo foi significativo por muitas razões, uma das quais foi à mudança no foco da pesquisa de insumos para resultados, que resultou da decisão dos autores de examinar como os recursos escolares afetavam a sua realização. Antes do relatório Coleman, a reforma da educação nos Estados Unidos, se concentrou unicamente na questão dos recursos, partindo do pressuposto de que disposições mais generosas para os salários, instalações, livros de texto e suprimentos dos professores "consertariam" as escolas da nação. Após a divulgação do relatório Coleman, os reformadores avançaram em uma ampla gama de propostas, muitas das quais buscavam mudanças no desempenho ao invés de (ou além de) aumentos de recursos. A mudança de foco dos insumos (recursos) para os resultados foi facilitada pelo aumento da disponibilidade dos resultados dos testes.

Destacamos ainda que os autores Evers e Walberg (2002) que, nesta obra, apresentam um conjunto de contribuições, sobre a temática da responsabilização, por autores especialistas em estudos de educação a partir das perspectivas das ciências sociais e comportamentais: história, economia, ciência política e psicologia.

Após está breve síntese da accountability nos Estados Unidos, retomamos as iniciativas de responsabilização (accountability) no Brasil. Conforme Brooke e Cunha (2015),

O Plano de Ações Articuladas - PAR implantado pelo MEC em 2007 e que contemplava, originalmente, os municípios considerados prioritários em função do IDEB alcançado em 2005, pode ser classificado aqui como uma política de alocação de recursos federais com base nos resultados da avaliação externa. Com a extensão do plano para todos os municípios, a política adquiriu conotações de accountability (BROOKE; CUNHA, 2015, p. 459).

A accountability é uma política de responsabilização com atribuição de consequências para os agentes escolares. Podemos citar como exemplos de políticas de responsabilização educacional: a bonificação docente - em função do atingimento de metas; a premiação de alunos ou escolas - com destacado desempenho positivo nas avaliações em larga escala e; a aplicação de sanções e intervenções em escolas - que não tenham atingido as metas determinadas.

Destacamos ainda a contribuição de Brooke e Cunha (2011), de que a

[...] accountability no contexto educacional significa acima de tudo a associação entre resultados de aprendizagem e consequências para o distrito educacional, a escola, os professores ou os alunos. O grau de pressão que a autoridade educacional deseja aplicar ao processo de indução pode ser calibrado de acordo com o tipo ou a seriedade das consequências. Nesse contexto, é comum rotular os níveis de pressão/indução mais altos de highstakes e os mais baixos de low-stakes, usando a palavra inglesa stakes, que 
significa "o valor colocado em jogo pelo apostador" (BROOKE; CUNHA, 2011, p. 22).

Os autores citados destacam também que em alguns estados como Ceará, Pernambuco e Amazonas foram criados prêmios para escolas com melhores resultados nas avaliações estaduais e, até municipais, como a da cidade do Rio de Janeiro em 2010 (BROKE; CUNHA, 2015). Além dos prêmios, foram criados em vários estados o bônus para os professores das escolas que atingiram as metas estabelecidas. O estudo de Capocchi (2017) apresenta quadro com tipos de bonificação docente no Brasil por unidades da federação. No estado de São Paulo a Bonificação por Resultados (BR) foi implantada em 2008, a partir do cumprimento de metas para o SARESP (SÃO PAULO, 2008).

Após estas considerações iniciais, apresentamos que o objetivo deste estudo é identificar se os resultados do SARESP 2016, do $9^{\circ}$ ano do ensino fundamental, foram discutidos entre gestores e professores das escolas selecionadas e quais foram os encaminhamentos; verificar também se as escolas realizam a avaliação institucional. A pesquisa foi desenvolvida em uma abordagem qualitativa. A metodologia utilizada é a pesquisa bibliográfica, pesquisa documental (Boletim Pedagógico, Atas das reuniões, Instrumento de Avaliação Institucional) e a coleta de dados (entrevistas semiestruturadas com gestores e professores).

Para desenvolver este estudo, optamos por iniciar abordando a criação do SARESP e suas fases. Na sequência apresentamos os resultados disponibilizados no Boletim Pedagógico do SARESP 2016 e o encaminhamento identificado nas escolas pesquisadas. Abordamos também como é realizada a avaliação institucional.

\section{O contexto de criação do SARESP e suas fases}

A criação do SARESP foi uma iniciativa da política educacional paulista na gestão da secretária de Educação Teresa Roserley Neubauer da Silva, no Governo Mário Covas. Bauer (2006) nos explicita o contexto em que o SARESP estava inserido:

O Sistema de Avaliação do Rendimento Escolar do Estado de São Paulo (SARESP) é organizado, em 1996, como uma iniciativa inserida em um projeto político mais ousado dos gestores de rede, de revisão e modificação do sistema educacional público paulista, anunciado através do documento "Diretrizes Educacionais para o Estado de São Paulo" no período de janeiro de 1995 a 31 de dezembro de 1998 e divulgado através do Comunicado SE, de 22/03/1995 (BAUER, 2006, p. 76). 
A autora complementa que este Comunicado da Secretaria de Educação informa que o sistema estadual precisava de reformas urgentes pois os serviços oferecidos não eram de qualidade e a gestão não ocorria de forma eficiente. Diante do contexto apresentado, a criação SARESP seria uma das estratégias de intervenção para o enfrentamento dos problemas elencados. A Resolução SE n. 27. de 29 de março de 1996, define o seu objetivo:

- Subsidiar a Secretaria de Educação na tomada de decisão quanto à política educacional;

- Verificar o desempenho dos alunos da Educação Básica para fornecer informações a todas as instâncias do sistema de ensino que subsidiem a capacitação dos recursos humanos do magistério; a reorientação da proposta pedagógica das escolas, de modo a aprimorá-la, a viabilização da articulação dos resultados da avaliação com o planejamento escolar, capacitação e estabelecimento de metas para o projeto de cada escola (SÃO PAULO, 1996).

Pelo que podemos apreender o objetivo pretendido visava servir de referência para elaboração de políticas da SEE e subsidiar o trabalho pedagógico nas escolas.

O SARESP é realizado anualmente desde 1996, exceto nos anos de 1999 e 2006, e tendo modificações quase todos os anos. São avaliadas as escolas estaduais, obrigatoriamente, e por adesão, as escolas particulares e municipais (com exceção de 2001 e 2002, quando só foram avaliadas as escolas estaduais).

Além das provas, também são aplicados questionários de contextualização, com alunos e suas famílias, professores e equipe de gestão. A análise permite o agrupamento dos dados obtidos por classes, depois por escola, mais tarde por cidade, município, diretorias regionais e totalizadas para o sistema, ou seja, para o Estado e correlacioná-los com o desempenho dos estudantes.

A edição de 2006 foi cancelada pela recém empossada secretária Maria Lúcia Marcondes Vasconcelos que substituiu Gabriel Chalita no comando da Secretaria Estadual de Educação de São Paulo - SEE/SP. A secretária alegou a necessidade de analisar os resultados e rever o modo como a avaliação vinha sendo desenvolvida.

Em 2007 foi divulgado também a criação do IDESP - Índice de Desenvolvimento da Educação do Estado de São Paulo.

Cabe destacar ainda, que neste ano (2008), os resultados do SARESP são atrelados às bonificações de professores e ao cumprimento de metas do IDESP, conforme anunciamos anteriormente (Bonificação por Resultados).

A Resolução SE no 41/2011, estabeleceu os procedimentos para a realização do SARESP neste ano. As disciplinas avaliadas foram Língua Portuguesa, Matemática, História, Geografia e Redação (SÃO PAULO, 2011a). 
Cabe destacar ainda, que neste ano, a Resolução $n^{\circ}$ 73/2011, instituiu o Prêmio "Saresp 2011", destinado aos alunos concluintes do Ensino Médio regular, com o objetivo de incentivar maior participação e envolvimento desses estudantes nas avaliações do Saresp. A premiação foi de 12.000 notebooks (Art. $4^{\circ}$ ) (SÃO PAULO, 2011b).

No ano 2014, foi mantido, o mesmo formato, ou seja, as mesmas turmas avaliadas, alterando apenas as disciplinas de Ciências Humanas para Ciências (no Ensino Fundamental) e Ciências da Natureza (Biologia, Física e Química) no Ensino Médio (SÃO PAULO, 2014).

No ano seguinte, o SARESP avaliou apenas as disciplinas de Língua Portuguesa e Matemática. Enfatizamos ainda que o SARESP foi aplicado de forma censitária, abrangendo a totalidade dos alunos do ensino regular, de todos os turnos das classes/anos/série das escolas envolvidas ( $3^{\circ}, 5^{\circ}, 7^{\circ} / 6^{\mathrm{a}}, 9^{\circ} / 8^{\mathrm{a}}$ do Ensino fundamental e $3^{\mathrm{a}}$ série do Ensino Médio), exceto aos alunos do $7^{\circ}$ ano do ensino fundamental da rede de ensino da Secretaria da Educação, para os quais a aplicação foi por amostragem (SÃO PAULO, 2015).

Nos anos de 2016 e 2017, o SARESP foi aplicado aos mesmos alunos e nas mesmas disciplinas do ano de 2015. Entretanto, os questionários contextuais dirigidos a alunos, professores e escola deixaram de ser aplicados, conforme consta no Relatório SARESP de 2017, comprometendo a contextualização dos dados aferidos pelas provas aplicadas.

Após está breve retrospectiva história, destacamos a posição de Calderón e Oliveira Junior (2012) que defendem à existência de três momentos do SARESP em seu ascendente percurso enquanto principal política avaliativa em larga escala. Para os autores, o primeiro período ocorreu entre 1996 e 2002, o segundo entre 2003 e 2007, e o último a partir de 2008 (que considera até o ano de 2012).

O primeiro se refere a sua formação identitária no contexto do pioneirismo das avaliações em larga escala no Brasil. O segundo caracteriza-se pela instabilidade gerencial, com destaque para as trocas no comando tanto na Secretaria de Educação como no Governo paulista. O terceiro caracteriza-se pela estabilidade num contexto de hiperpragmatismo gerencial (CALDERÓN; OLIVEIRA JÚNIOR, 2012, p. 1).

O último período foi marcado pelo processo de reestruturação do SARESP sob a gestão de Maria Helena Guimarães Castro a partir de 2008. Ações como a criação do IDESP, de Matrizes de Referência para o SARESP, do Programa de Qualidade da Escola (PQE), dentre outros, que apontavam para a crescente valorização dos resultados, particularmente na gestão do governador Serra (2007-2010).

Em nossa análise, a crescente valorização dos resultados permanece nas duas gestões consecutivas do governador Alckmin, confirmando a estabilidade do SARESP como política 
de avaliação em larga escala paulista, registrando que em 2017, foi aplicada a vigésima edição do SARESP. Conforme o Sumário Executivo do SARESP 2017, está edição envolveu 6.294 escolas e foi organizado a publicação do "SARESP 2017 em Revista".

No tópico a seguir, nos debruçamos sobre os resultados do SARESP de 2016, disponibilizados no Boletim Pedagógico de 2016, e a coleta de dados em quatro escolas públicas estaduais no ano de 2017. A busca dos resultados para subsidiar a gestão educacional e a reflexão para aprimoramento pedagógico vem sendo perseguida há vários anos. Desde sua criação o SARESP tinha como objetivo a reorientação da proposta pedagógica das escolas, de modo a aprimorá-la, ou seja, a viabilização da articulação dos resultados da avaliação com o planejamento escolar.

Brooke e Cunha (2015) discutem a necessidade de reflexão sobre os resultados da avaliação de sistema pelo coletivo da escola. Os autores apresentam que as Secretarias de Educação tentam suprir esta lacuna emitindo materiais informativos que tentam traçar um diagnóstico do nível de aprendizagem dos alunos. Destacam também dois materiais: Boletins Pedagógicos e Relatórios. Informam ainda, que mesmo com a evolução da qualidade dos Boletins Pedagógicos e em alguns casos, a criação de um dia específico para estudo coletivo do material devolutivo pela escola, "a divulgação dos resultados não redunda automaticamente na sua apropriação por parte dos professores" (BROOKE; CUNHA, 2015, p. 360).

Diante deste contexto apresentado, enfatizamos a necessidade das avaliações de larga escala terem significado para os professores, e, portanto, questionamos: os resultados do SARESP 2016 do $9^{\circ}$ ano do ensino fundamental das escolas pesquisadas foram discutidos entre gestores e professores? Quais foram os encaminhamentos? As escolas pesquisadas realizam avaliação institucional?

\section{As escolas pesquisadas: entre o previsto e o realizado}

Neste tópico apresentamos os resultados do SARESP de 2016, dos anos finais do ensino fundamental, disponibilizados pelo Boletim Pedagógico do SARESP 2016, e o encaminhamento obtidos na coleta de dados de quatro escolas estaduais de uma cidade do oeste do Estado. Averiguamos também se as unidades pesquisadas realizam a avaliação institucional.

O documento tomado por base, ou seja, o Boletim Pedagógico, apresenta a escala de proficiência do SARESP em quatro níveis de proficiência - abaixo do básico, básico, adequado e avançado. 
O nível abaixo do básico é classificado como insuficiente e indica que os alunos apresentam domínio insuficiente de conteúdo, das competências e das habilidades desejáveis para o ano/série escolar. O nível básico é classificado como suficiente e indica que os alunos demonstram domínio mínimo dos conteúdos, das competências e das habilidades, mas que possuem as estruturas necessárias para interagir com a proposta curricular no ano/série subsequente. O nível adequado é classificado como suficiente e indica que os alunos demonstram domínio pleno dos conteúdos, das competências e habilidades desejáveis para o ano/série escolar em que se encontram. O nível avançado, Quadro 1, é classificado como avançado e indica que os alunos demonstram conhecimentos e domínio de conteúdo, das competências e habilidades acima do requerido para o ano/série escolar em que se encontram. Apresentamos as classificações, pois de acordo com o nível de proficiência, o Boletim Pedagógico vai orientar a medida a ser tomada como encaminhamento pedagógico.

Quadro 1 - Níveis de proficiência - Medida a ser tomada

\begin{tabular}{|c|c|}
\hline Abaixo do Básico & Recuperação Intensiva \\
\hline Básico & Recuperação Continuada \\
\hline Adequado & Aprofundamento \\
\hline Avançado & Desafio \\
\hline
\end{tabular}

Fonte: autora

Destacamos também, Quadro 2, a Escala de desempenho do $9^{\circ}$ ano no Ensino Fundamental (de 0 a 400 pontos) para Língua Portuguesa e Matemática que são as seguintes:

Quadro 2 - Escala de desempeho

\begin{tabular}{|c|c|c|}
\hline & Língua Portuguesa & Matemática \\
\hline Abaixo do Básico & $<200$ & $<225$ \\
\hline Básico & $200 \mathrm{a}<275$ & $325 \mathrm{a}<300$ \\
\hline Adequado & $275 \mathrm{a}<325$ & $<=350$ \\
\hline Avançado & $<=325$ & $<=350$ \\
\hline
\end{tabular}

Fonte: autora

Após estes esclarecimentos sobre a escala de proficiência do SARESP e escala de desempenho do $9^{\circ}$ ano do ensino fundamental, apresentamos os resultados das quatro escolas pesquisadas. Para análise do Relatório Pedagógico do SARESP 2016 e da coleta de dados 
denominaremos aleatoriamente de escola A, B, C e D. Informamos que as escolas pesquisadas são de uma cidade do oeste do Estado, possuem o número máximo de 500 alunos e estão localizadas na periferia, aproximadamente em seus extremos, nos sentidos norte-sul e lesteoeste.

Na escola A, a média do desempenho em Língua Portuguesa foi de 217,7 pontos e em Matemática 247,5 pontos. Participaram 88 alunos do $9^{\circ}$ ano do ensino fundamental no SARESP 2016.

Na escola B, a média do desempenho em Língua Portuguesa foi 203,9 pontos e em Matemática 224,7 pontos. Participaram 45 alunos do $9^{\circ}$ ano do Ensino Fundamental do SARESP 2016.

Na escola C, a média do desempenho em Língua Portuguesa foi 261,1 e em Matemática 270,6. Participaram 15 alunos do $9^{\circ}$ ano do Ensino Fundamental do SARESP 2016.

Na escola D, A média do desempenho em Língua Portuguesa foi 227,7 e em Matemática 247,8. Participaram 58 alunos do $9^{\circ}$ ano do ensino fundamental do SARESP 2016.

Conforme pode ser observado nas médias apresentadas nas quatro escolas, verificamos que três delas possuem o nível de proficiência básico e apenas uma delas, a escola B, ficou em matemática com o nível de proficiência abaixo do básico. Diante destes resultados, os encaminhamentos pedagógicos seriam recuperação continuada para três escolas e recuperação intensiva para uma delas segundo o Boletim Pedagógico do SARESP 2016 (SÃO PAULO, 2017).

De acordo com o documento citado, o objetivo do Boletim Pedagógico do SARESP é permitir que a escola análise seu desempenho e com o apoio da Secretaria Estadual de Educação, melhorar a qualidade da aprendizagem dos seus alunos. Estes resultados foram disponibilizados para as escolas no início de fevereiro de 2017. O planejamento anual ocorre no mês de fevereiro e o replanejamento no mês de julho.

Em setembro e outubro de 2017, realizamos a coleta de dados nas quatro escolas pesquisadas utilizando a entrevista semiestruturada. Na escola A, participaram dois gestores (as) e doze professores(as). Na Escola B, participaram dois gestores (as) e seis professores (as). A escola $\mathrm{C}$ contou com a participação de dois gestores (as) e seis professores (as). Na escola D, tivemos a participação de uma gestora e oito professores, conforme informações da gestora havia sido cortado um gestor em função do número de alunos da escola. Utilizamos o código AG1, para designar o gestor 1 da escola A, AP1, para designar o professor 1 da escola A, BG1, gestor 1 da escola $\mathrm{B}$, do mesmo modo para as demais escolas. 
$\mathrm{Na}$ entrevista foi perguntando se tinham recebido o Boletim Pedagógico com os resultados do SARESP de 2016? Na escola A, os gestores (as) responderam que sim e apenas o professor AP11 disse "Não me lembro". Na escola B, gestores e professores responderam que sim. $\mathrm{Na}$ escola $\mathrm{C}$, os gestores e professores responderam que sim. $\mathrm{Na}$ escola $\mathrm{D}$, a gestora respondeu que sim e dois professores responderam que não (DP4, DP5).

Foi perguntado também se houve discussão dos resultados do SARESP de 2016 e quando ocorreu? Os gestores das escolas responderam que os resultados do SARESP foram discutidos na Aula de Trabalho Pedagógico Coletivo (ATPC), no planejamento e no replanejamento. Entretanto, destacamos que as respostas não foram homogêneas, dois gestores responderam apenas no replanejamento e em ATPCs. "Sim. - Replanejamento, ATPC(s)" (AG2). Do mesmo modo, "Sim. Replanejamento e ATPC" (DG1). Cabe destacar que o replanejamento ocorre no mês de julho e, portanto, a recuperação continuada dos alunos que tiveram nível de proficiência básico no SARESP 2016 pode ter sido comprometida. Em relação aos professores, a maioria respondeu que foram discutidos no ATPC, no planejamento e replanejamento. Apenas três docentes, do total de 32, responderam que não, ou que não estava presente. Entretanto, foi solicitado às escolas pesquisadas as atas das ATPC(s) e da reunião de planejamento e replanejamento para comprovarmos se constava como item de pauta os resultados do SARESP 2016. Apenas uma escola, forneceu cópia das atas, nas quais foi identificado como item de pauta, uma reunião de ATPC no mês de fevereiro de 2017 e na reunião de planejamento anual. As demais escolas ficaram de enviar as atas por e-mail, mas não forneceram.

$\mathrm{Na}$ sequência foi perguntado quais os encaminhamentos, ou seja, que ações foram adotadas para recuperação continuada dos alunos que não alcançaram a aprendizagem requerida?

Recuperamos algumas respostas dos gestores:

"Os resultados são utilizados todos os anos em
planejamento/replanejamento. Identificando as principais dificuldades são
montados Planos de Ações a cada bimestre em ATPC. Os alunos abaixo do
básico são encaminhados para os projetos existentes (Ex.: Novo Mais
Educação)". (AGl)
"Recuperação continua; atividades de apoio à aprendizagem; avaliações
bimestrais (simulados e suas devolutivas aos alunos; encaminhamento de
alunos ao Programa Novo Mais Educação)". (CG1)
"Após análise dos boletins e da realidade da escola, elaboramos projetos e
planos de ação para que todas as disciplinas colaborem na recuperação da
aprendizagem". (DG1)

Selecionamos também algumas respostas dos professores: 
"Sim foram construídas coletivamente ações como análise dos erros e acertos juntamente com os alunos, priorizando e identificando habilidades que precisam ser trabalhadas em todas as disciplinas". (AP3)

"Os 15 primeiros dias do ano letivo foi para retomar as habilidades não atingidas pelos alunos, conforme os levantamentos passados pela coordenação". (BP4)

"Após identificação dos alunos de nível básico e abaixo do básico estes são convidados a participar, no contraturno, das atividades de recuperação em Matemática e Português do Programa Novo Mais Educação. Por turma são identificadas as dificuldades predominantes, os professores propõem em ATPC, formas e estratégias metodológicas para trabalhar em sua disciplina". (CP4)

"Eu pessoalmente não utilizo os boletins do SARESP porque acredito que a defasagem dos alunos é generalizada, portanto deve haver uma mudança no sistema todo de ensino e não só avaliar o SARESP”. (DP4)

Pelo que pudemos apreender nas entrevistas realizadas, os resultados são apresentados e discutidos nas escolas pesquisadas, particularment após a divulgação dos resultados e no planejamento anual. Entretanto, a recuperação continuada que é a recomendação do Boletim Pedagógico para alunos cujo nível de proficiência foi básico, acaba sendo realizada no Programa Novo Mais Educação do governo federal que ocorre no contraturno da escola.

Enfatizamos também que a escola B, que o encaminhamento seria a recuperação intensiva, pois o resultado do SARESP de 2016 mostrou nível de proficiência abaixo do básico na disciplina de Matemática, não realizou nenhuma ação adicional além do envio dos alunos ao Programa Novo Mais Educação. Uma das coordenadoras também colocou um problema adicional que é o fato de alguns pais não deixam o filho ficar no contraturno, ou seja, aqueles que não participam do Programa Mais Educação vão ficar sem nenhuma alternativa de recuperação.

Interessou saber também se após o processo de recuperação continuada houve nova avaliação dos alunos com o nível de proficiência básico e abaixo do básico (na escola B) e se foi discutido novamente no replanejamento? Destacamos uma amostra das respostas dos professores:

\footnotetext{
"Sim, constantemente são avaliados os resultados em reuniões de planejamento, ATPCs (ação $\rightarrow$ reflexão $\rightarrow$ ação)". (AP3)

"Não tivemos a oportunidade de rever os resultados, após traçadas as novas ações". (AP7)

"Logo após, houve também a aplicação da AAP (Avaliação da Aprendizagem em Processo), na qual foi possivel verificar se as habilidades foram contempladas ou não". (BP2)

"Sim, logo após foi aplicado as AAPs (Avaliação da Aprendizagem em Processo), avaliando as habilidades não contempladas". (BP4)
} 


\begin{abstract}
"Os resultados e ações são retomados a todo momento. É prioridade e é realizada por todos os docentes da turma. Não ficando a recuperação somente a cargo dos professores de Matemática e Língua Portuguesa". (CP3) "A avaliação é continua. Além da(s) Avaliação(ões) Aprendizagem Processo (AAPs) ao longo do ano letivo, as avaliações de cada disciplina acompanham o progresso dos alunos e os resultados são discutidos em ATPC e de forma mais completa no replanejamento". (CP4)

"Sim, sempre é feito a recuperação, pois nossos alunos têm muita defasagem no aprendizado pelo histórico da comunidade". (DP1)

"Sim, a recuperação dos alunos foi discutida no replanejamento". (DP2)
\end{abstract}

De modo geral, várias das respostas do conjunto dos professores são genéricas, ou seja, não possibilita a identificação de uma ação específica de nova avaliação. Entretanto, alguns destacaram a Avaliação de Aprendizagem e Processo (AAP) que ocorre bimestralmente na rede estadual como um aspecto positivo e complementar aos resultados do SARESP pelos professores entrevistados.

E finalizamos a entrevista com a pergunta: A escola possui avaliação institucional? Quem participa e quando ela ocorre? Dos oito gestores entrevistados, um deles disse que não sabia pois estava em outra escola, um respondeu que realizavam Avaliação da Aprendizagem em Processo (AAP) e os demais responderam que sim e que era utilizado a avaliação encaminhada pela Diretoria de Ensino. Em relação aos professores, a maioria respondeu que sim e que ocorria no último dia do ano e utilizavam o instrumento disponibilizado pela diretoria de ensino. Apenas quatro docentes disseram que não sabiam. Apenas dois professores de uma mesma escola (a escola A), responderam diferente: "participava alunos do $9^{\circ}$ ano do fundamental e $3^{\circ}$ série do Ensino Médio sempre em setembro" (AP7) e "Gostaríamos de elaborar e uma das questões que elencamos foi a autoavaliação que prof. X (Artes) já aplica (da/na) Fundação Y. Ser estendida aos demais anos como forma de conhecermos melhor e mais profundamente nossa clientela" (AP10). Desse modo, apenas uma escola se referiu a outro modelo de avaliação institucional que não utiliza o modelo da Diretoria de Ensino.

Pelo que pudemos apreender, as escolas pesquisadas utilizam o "Instrumento de Avaliação Institucional” encaminhado pela Diretoria de Ensino com cinco dimensões a ser avaliadas: dimensão pedagógica, gestão participativa, gestão de recursos humanos, gestão de recursos físicos e financeiros e gestão dos resultados educacionais. O documento (um questionário) possui nove páginas com perguntas discursivas e participam Diretores(as), vicediretores(as), Professor(es)(as) Coordenador(es)(as) e Professores(as). Em relação à forma como a avaliação institucional é realizada, as escolas pesquisadas disponibilizam o último dia de aula para esta finalidade e nos pareceu que ocorre burocraticamente. Tivemos acesso apenas 
ao instrumento (modelo), mas não aos seus resultados, que não foram disponibilizados. Nos apoiamos em Sousa (1995) que define a Avaliação Institucional como

[...] um processo de busca de compreensão da realidade escolar, com o fim de subsidiar a tomada de decisão quanto ao direcionamento das intervenções, visando ao aprimoramento do trabalho escolar. Como tal, a avaliação compreende a descrição, interpretação e o julgamento das ações desenvolvidas, resultando na definição de prioridades a serem implementadas e rumos a serem seguidos, tendo como referência princípios e finalidades estabelecidos no projeto da escola, ao tempo em que subsidia a sua própria definição (SOUSA, 1995, p. 63).

Portanto, o que foi identificado se distancia completamente do que compreendemos por avaliação institucional.

\section{Considerações finais}

Conforme entrevistas nas escolas pesquisadas a recuperação dos alunos com proficiência no SARESP básica ou abaixo do básico nos pareceu restrita aos professores das disciplinas de Língua Portuguesa e Matemática. O Boletim Pedagógico do SARESP 2016, indica a recuperação continuada para a proficiência básica e recuperação intensiva para a proficiência abaixo do básico. Na escola com proficiência abaixo do básico na disciplina de Matemática não foi identificada nenhuma ação de recuperação intensiva. Nas demais escolas foi oferecida a recuperação continuada no Programa Novo Mais Educação que é realizada por outro professor no contraturno. Identificamos em uma das escolas que o professor da disciplina de matemática não conseguia se encontrar com o do contraturno da recuperação. Ele tinha aula em outra escola e os horários eram incompatíveis. Acrescentamos ainda, a informação que alguns pais não permitem que os alunos fiquem no contraturno e, portanto, ficam sem a recuperação. Ficou evidenciado também que no Replanejamento não há uma ação específica, ou seja, uma nova avaliação para subsidiar o processo de recuperação. Embora alguns professores tenham mencionado a Avaliação de Aprendizagem e Processo (AAP) como complementar aos resultados do SARESP.

Enfim, estes aspectos acabam por comprometer a recuperação "de fato" dos alunos que ficaram com o nível de proficiência abaixo do básico ou básico. Do mesmo modo, o que é denominado por avaliação institucional não consiste "de fato" em um processo de busca pela compreensão da realidade escolar. Identificamos a necessidade da avaliação institucional, ou 
seja, o coletivo da escola, analisar os resultados da avaliação de sistema, debruçar-se sobre estes dados, validá-los e encontrar formas de encaminhamento ao professor, de modo a oferecer subsídios à avaliação em sala de aula. Destacamos a ênfase na avaliação institucional sobre os resultados da avaliação de sistema para monitorar/apoiar a aprendizagem dos alunos. Entretanto, ressaltamos a necessidade de outros indicadores qualitativos elencados pelo coletivo que contribuam para o resgate da finalidade da escola e que possam subsidiar a gestão escolar.

\section{REFERENCIAS}

ARCAS, P. H. Implicações da progressão continuada e do SARESP na avaliação escolar: tensões, dilemas e tendências. Tese (Doutorado em Educação) - Faculdade de Educação, Universidade de São Paulo, São Paulo, 2009.

BAUER, A. Usos dos resultados do SARESP: o papel da avaliação nas políticas de formação docente. 2006. 172 f. Dissertação (Mestrado em Educação), Universidade de São Paulo (USP), São Paulo, 2006.

BAUER, A. Uso dos Resultados do SARESP e Formação de Professores: a visão dos níveis centrais. In: BROOKE, N.; ALVES, M. T. G.; OLIVEIRA, L. K. M. (orgs.) A Avaliação da Educação Básica: a experiência brasileira. Belo Horizonte: Fino Traço, p. 381-386, 2017.

BAUER, A; SOUSA, S. Z. L.; HORTA NT, J. L.; VALLE, R.; PIMENTA, C. O. Iniciativas de avaliação do ensino fundamental em municípios brasileiros: mapeamento e tendências. Revista Brasileira de Educação, v. 22, p. 1-19, 2017.

BROOKE, N.; CUNHA, M. A. A avaliação externa como instrumento da gestão educacional nos estados. Estudos \& Pesquisas Educacionais, v. 2, p. 17-79, 2011.

BROOKE, N.; CUNHA, M. A Avaliação Externa como Instrumento da Gestão Educacional nos Estados. In: BROOKE, N.; ALVES, M. T. G.; OLIVEIRA, L. K. M. (orgs.) A Avaliação da Educação Básica: a experiência brasileira. Belo Horizonte: Fino Traço, p. 359-364, 2015.

CALDERÓN, A. I.; OLIVEIRA JUNIOR, R. G. Sistema de avaliação e rendimento escolar do estado de São Paulo: uma abordagem na linha do tempo. In: III III Congresso Ibero Americano de Política e Administração da Educação, 2012, Zaragoza. Cadernos ANPAE. Recife: Biblioteca ANPAE, v. 15. p. 1-16, 2012.

CAPOCCHI. E. R. Avaliações em larga escala e políticas de responsabilização na educação: evidências de implicações indesejadas no Brasil. 214 p. 2017. Dissertação (Mestrado em Educação). Faculdade de Educação da universidade de São Paulo, São Paulo, 2017.

EVERS, Williamson M.; WALBERG, Herbert J. School accountability. Stanford: Hoover Institution Press, 2002. 
RAVITCH, D. Testing and Accountability Historically Considered. In: EVERS, Williamson M.; WALBERG, H. J. School accountability. Stanford: Hoover Institution Press, p. 9-22, 2002.

SÃO PAULO. SEE. Resolução SE n. 27, de 29 de março de 1996. Dispõe sobre o Sistema de Avaliação de Rendimento Escolar do Estado de São Paulo. Disponível em:

http://siau.edunet.sp.gov.br/ItemLise/arquivos/27_1996.htm. Acesso em: 20 jul. 2017.

SÃO PAULO. Lei Complementar n. 1078, de 17 de dezembro de 2008. Institui a Bonificação por Resultados- BR, no âmbito da Secretaria da Educação. Disponível em: http://www.legislacao.sp.gov.br/legislacao/dg280202.nsf/6279925b177ee40183256b6f00692f 13/a2898744a65659d903257523004bf8c1?OpenDocument. Acesso em: 31 jan. 2018.

SÃO PAULO. Resolução SE n. 41, de 31 de julho de 2014. Dispõe sobre a realização das provas de avaliação relativas ao Sistema de Avaliação de Rendimento Escolar do Estado de São Paulo - SARESP/2014. Disponível em:

http://file.fde.sp.gov.br/saresp/saresp2014/Arquivos/Resolu\%C3\%A7\%C3\%A3o\%20SE\%204 1_14_SARESP2014.pdf. Acesso em: 31 jan. 2019.

SÃO PAULO. Resolução SE n. 41, de 18 de agosto de 2015. Dispõe sobre a realização das provas de avaliação relativas ao Sistema de Avaliação de Rendimento Escolar do Estado de São Paulo - SARESP/2015. Disponível em:

http://file.fde.sp.gov.br/saresp/saresp2015/Arquivos/RESOLU\%C3\%87\%C3\%83O_SE_41_S ARESP_2015.pdf. Acesso em: 31. jan. 2018.

SÃO PAULO. Boletim Pedagógico do SARESP de 2016. Disponível em:

http://saresp.fde.sp.gov.br/2016/ Acesso em 20 jul. 2017.

SÃO PAULO. Sumário Executivo do SARESP 2017. Disponível em: http://saresp.fde.sp.gov.br/2017/Arquivos/sumario_executivo_15_junho.pdf. Acesso em: 31 jan. 209.

SÃO PAULO. IDESP. Disponível em: http://www.educacao.sp.gov.br/idesp Acesso em 28 maio 2018.

SOUSA. S. Z. Avaliação escolar: constatações e perspectivas. Revista de Educação AEC, Brasília: AEC do Brasil, ano 24, n. 94, p. 59-66, jan./mar. 1995.

\section{Como citar este artigo}

SABIA, Cláudia de Pádua Pereira. O uso dos resultados do SARESP como instrumento de gestão escolar: boletim pedagógico e avaliação institucional. Revista on line de Política e Gestão Educacional, Araraquara, v. 23, n. 3, p. 665-679, set./dez., 2019. e-ISSN:1519-9029. DOI: $10.22633 /$ rpge.v23i3.12896

Data de Submissão: 06/04/2019

Revisões Requeridas: 10/05/2019

Aceite em: 05/06/2019

Publicado em: 15/08/2019 